\title{
Abnormal eye movements in three types of chorea
}

\author{
Anormalidades dos movimentos oculares em três tipos de coreia \\ Tiago Attoni', Rogério Beato², Serge Pinto ${ }^{3}$, Francisco Cardoso²
}

\begin{abstract}
Chorea is an abnormal movement characterized by a continuous flow of random muscle contractions. This phenomenon has several causes, such as infectious and degenerative processes. Chorea results from basal ganglia dysfunction. As the control of the eye movements is related to the basal ganglia, it is expected, therefore, that is altered in diseases related to chorea. Sydenham's chorea, Huntington's disease and neuroacanthocytosis are described in this review as basal ganglia illnesses that can present with abnormal eye movements. Ocular changes resulting from dysfunction of the basal ganglia are apparent in saccade tasks, slow pursuit, setting a target and anti-saccade tasks. The purpose of this article is to review the main characteristics of eye motion in these three forms of chorea.
\end{abstract}

Keywords: chorea; eye movements; Huntington disease; neuroacanthocytosis.

\section{RESUMO}

Coreia é um movimento anormal caracterizado pelo fluxo contínuo de contrações musculares ao acaso. Este fenômeno possui variadas causas, como processos infecciosos e degenerativos. A coreia resulta de disfunção dos núcleos da base, os quais estão envolvidos no controle da motricidade ocular. É esperado, então, que esta esteja alterada em doenças com coreia. A coreia de Sydenham, a doença de Huntington e a neuroacantocitose são apresentadas como modelos que têm por característica este distúrbio do movimento, por ocorrência de processos que acometem os núcleos da base. As alterações oculares decorrentes de disfunção dos núcleos da base se manifestam em tarefas de sacadas, perseguição lenta, fixação de um alvo e em tarefas de antissacadas. O objetivo deste artigo é revisar as principais características dos movimentos oculares nestas três formas de coreias.

Palavras-chave: coreia; movimentos oculares; doença de Huntington; neuroacantocitose.

Chorea is an abnormal movement characterized by a continuous flow of random involuntary muscle contractions. This phenomenon has several causes, such as infectious and degenerative conditions. Chorea results from dysfunction of the basal ganglia, which are involved in the control of eye movements. It is, therefore, expected that the control of eye movements is changed in diseases with chorea. Frontal areas are often abnormal in choreatic diseases due to the connections between the basal ganglia and frontal lobe. The causes of chorea are varied, but its presentation does not change, even in different pathologies. There are non-genetic and genetic causes for chorea ${ }^{1}$. Among the former is Sydenham's chorea (SC), the most common cause of chorea in children, while Huntington's disease (HD) and neuroacanthocytosis (NA) chorea are of genetic origin ${ }^{1,2}$.

Sydenham's chorea is the neurologic manifestation of rheumatic fever (RF), presumably caused by antibodies against group
A beta-hemolytic streptococci, which cross-react with the epitopes of the basal ganglia ${ }^{3}$. There has been an overall decline in the incidence of SC, even in developing countries, where it used to be endemic. However, it remains the most common cause of chorea in children, worldwide ${ }^{4}$. The SC patients show a combination of motor disorders (chorea, decreased muscle tone, tics and others) and cognitive and behavioral changes. Among the latter are obsessions, hyperactivity and executive dysfunction ${ }^{5}$.

Huntington's disease is a neurodegenerative disorder inherited in an autosomal dominant pattern, whose gene was mapped in the region of the gene IT-15 on chromosome 4 p16.3. Although the underlying mechanism responsible for cell death has not been determined, there is an unstable expansion of the trinucleotide CAG that leads to the production of an abnormally large protein, huntingtin 6 . The onset of the disease can occur at any age; however, in most cases, patients develop early

${ }^{1}$ Universidade Federal de Minas Gerais, Programa de Pós-Graduação em Neurociências, Belo Horizonte MG, Brasil;

${ }^{2}$ Universidade Federal de Minas Gerais, Departamento de Medicina Interna, Serviço de Neurologia, Belo Horizonte MG, Brasil;

${ }^{3}$ Aix-Marseille Université /CNRS, Laboratoire Parole et Langage, Aix-en-Provence, France.

Correspondence: Francisco Cardoso; Av Pasteur 89/1107; 30150-290 Belo Horizonte MG, Brasil; E-mail: cardosofe@terra.com.br

Support: Dr Cardoso has received honoraria from Boehringer-Ingelheim, UCB, and TEVA.

Conflict of interest: There is no conflict of interest to declare.

Received 21 March 2016; Accepted 16 May 2016. 
symptoms around 35 years of age. Typically, patients present with a triad of movement disorders (chorea, dystonia and others), cognitive decline and behavioral changes ${ }^{7,8}$.

The term NA encompasses a heterogeneous group of rare genetic diseases. The most common diseases in this group are chorea, acanthocytosis, McLeod syndrome, Huntington's disease-like 2 and pantothenate kinase-associated neurodegeneration. Most NA cases are inherited in an autosomal recessive manner, but some of the diseases are transmitted as a dominant trait linked to X chromosomes or are even autosomal dominant. Clinically, patients often have the triad found in HD, but other symptoms, such as orofacial self-mutilating dyskinesia, seizures and peripheral neuropathy are also occasionally found in these patients ${ }^{9}$.

Despite the heterogeneous clinical features of these conditions, the basal ganglia are the site of dysfunction in all of them. This anatomical area is involved not only with motor control but also in other functions, such as cognition, behavior and eye motion. Therefore, it is no surprise that patients with basal ganglia disorders often display a multitude of clinical characteristics in all these domains. Although the cognitive and behavioral disturbances associated with chorea have been thoroughly investigated, there are few data on disorders of ocular motility in chorea ${ }^{10,11,12,13}$.

The structures involved in eye motion are able to provide important information about the disease, but it is also necessary to investigate the function of these areas and their connections. It is known that the vertical and horizontal saccades are impaired in $\mathrm{HD}^{14}$. The superior colliculus plays an important role in the final execution of these movements, maintaining connections with the basal ganglia and cortical structures that exert a regulatory role on voluntary and reflexive saccades. The frontal cortex and the parietal cortex work together, allowing voluntary movement ${ }^{15}$. There is no involvement of the frontal cortex for the reflexive action, and its control is exerted solely by subcortical structures ${ }^{16}$. The frontal cortex has projections directed to the caudate nucleus, sending this information to the superior colliculus. Atrophy in these circuits explains part of the eye motion dysfunction present in $\mathrm{HD}^{14,17}$. The caudate seems to participate in the initiation and inhibition of saccadic movement in the horizontal and vertical planes. Imaging studies indicate involvement of the eye field cortex, the inferior parietal cortex and caudate nucleus ${ }^{18}$.

The study of eye motions in a progressive disease may reveal more insight into the structural dysfunction and provide information about the effectiveness of new treatments ${ }^{19,20}$.

The purpose of this article is to review ocular motility in SC, HD and NA, with emphasis on clinical and pathophysiological aspects. Before we start describing the results of studies related to each of these conditions, there are terms that need to be defined: rapid eye movements are called saccadic or saccades. Eye movements to detect a target in motion can be tested through the task of slow pursuit, which is to look for a moving point; and an antisaccade task, which consists of deletion or inhibition of a stimulus. With the appearance of the target, the subject has to look to the opposite side. Such tasks require a more refined cognitive performance as they involve a preparatory phase, inhibition and decision phase ${ }^{13}$. Munoz and $\mathrm{Coe}^{21}$, produced a model of the neural control of eye movements that can be seen in the Figure.

\section{SYDENHAM'S CHOREA}

There are very few studies of ocular movements in SC. We highlight two studies that identified abnormalities in tasks requiring eye movement in patients with SC.

Cardoso et al. ${ }^{5}$ examined 50 children with a confirmed diagnosis of RF, including 13 who developed SC. The average age of the 50 patients with RF was 8.4 years. Using clinical evaluation, the authors found the presence of hypometric saccade in $80 \%$ of patients with chorea, $13 \%$ in patients without chorea, $25 \%$ in patients with chorea in remission and in $13.5 \%$ of patients without RF chorea. Based on these results, the authors suggest that abnormalities of the ocular motility found in their study may reflect dysfunction of the connections between the basal ganglia and the superior colliculi. Considering the results in patients in remission, it is thought that this dysfunction may be transient, disappearing in most patients with chorea who go into remission. However, the presence of saccadic abnormalities in patients in SC remission supports the notion that the oculomotor system damage may be persistent in some individuals. Furthermore, hypometric saccades found in patients with RF without chorea, suggests that dysfunction of eye movement may occur independently of the movement disorder. Furthermore, the authors found an association between SC, carditis and alterations in eye movements.

The antisaccades task has also been explored in SC in another article by Cairney et al. ${ }^{22}$. This study explored the

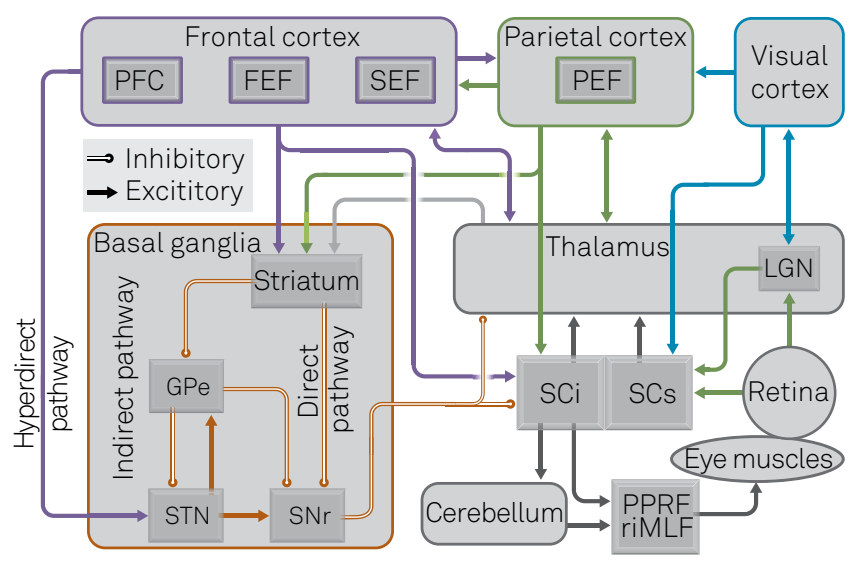

Figure. The neural control of eye movements (Munoz and Coe. EJN, 2011) 
possibility of residual neurological dysfunction in two SC patients in remission. They had a history of childhood SC, with the most recent episodes of chorea having occurred five and 17 years, respectively, before the test. They were compared to the performance of 33 control subjects matched for age. The subjects underwent neuropsychological assessment and an assessment of antisaccades. The eye movements were evaluated with the aid of a computer, which recorded the action, and a light emitting diode bar that produced the visual stimuli. Control individuals showed no signs of dysmetria or anticipatory saccades and had normal performance for the saccade duration, peak velocity in the normal saccade without antisaccade errors, and good recognition memory. However, in the antisaccade task, the two SC patients showed normal rates of errors, but high latency values in accomplishing the antisaccade task. These results confirm the hypothesis of Cardoso et al. ${ }^{5}$, of the presence of residual dysfunction of the oculomotor system in some patients with SC in remission.

\section{HUNTINGTON'S DISEASE}

Oculomotor abnormalities in HD were clinically identified in 1945 by Derceux ${ }^{23}$ and Andre-Thomas et al. ${ }^{24}$. During the clinical evaluation of patients with HD, the existence of severe impairment in eye movements, particularly in the vertical direction, were, observed. Since then there have been several studies of ocular motility in these patients that we summarize in this section.

Huntington's disease patients have difficulties initiating voluntary eye movements, tending to use compensatory movements with the head ("head impulse"). This was initially considered an oculomotor apraxia ${ }^{25,26,27,28,29}$. However, Becker et al. ${ }^{26}$ evaluated horizontal head movements and eye-head coordination in 29 early stage HD patients and 24 age-matched controls. Subjects were seated at the centre of a hemicylindrical screen with a radius of $1.60 \mathrm{~m}$ carrying a horizontal array of light emitting diodes at eye level that served as visual targets. Recordings of eye and head movements were made. Horizontal eye movements were recorded by electrooculography (EOG) using a pair of bitemporal electrodes. To record horizontal head movement, the subject wore a lightweight helmet coupled to a precision potentiometer above their head, allowing inclinations of the axis of head rotation. The test battery was created for saccadic movement and antisaccades. Although the subjects with HD made small involuntary head movements, these movements were not essential in generating saccades since they only occurred late after the saccade onset. Thus, the head movements of patients must be considered an adaptive behaviour.

The vertical and horizontal saccades are often impaired in HD patients ${ }^{28}$. Avanzini et al. ${ }^{29}$ examined 18 patients with HD using EOG, recording with pairs of silver chloride electrodes placed in the horizontal and vertical plane, coupled to an amplifier. The recordings were usually binocular for horizontal and monocular for vertical movements. Saccadic movements, fixation, smooth pursuit, optokinetic and vestibular responses were examined. When present, vertical saccades showed long latency, low amplitude, low velocity, and disturbances related to blinking. Voluntary saccades were slowed in patients with HD and were more disturbed in the vertical than the horizontal direction ${ }^{29,30,31,32}$.

In HD there is an increased latency, which is identified as a time delay at the onset of the movement, associated with the presence of hypometric ocular movements ${ }^{14,27,33,34,35}$. The loss of connections between the frontal eye field and the caudate nucleus of HD is hypothesized as being responsible for the increase in the latency of eye movements ${ }^{13,36,37,38,39}$. Ali et al. ${ }^{16}$, evaluated the saccadic movements of 24 patients with HD, and compared the results with 20 patients in a control group using binocular infrared stimulation. This device is attached to the patient's head and all eye movements are recorded by an auto-resolution camera. To measure the motor severity of patients with HD, the Unified Huntington Disease Rating Scale (UHDRS) was applied. The results showed an increase in latency of saccadic movement, and a correlation between the engine index obtained in the HD scale and the value found in the analysis of eye latency. This result confirms the involvement of the fronto-striatal circuit in the initiation process of the saccades.

Another important point is the reduction of speed of these movements ${ }^{25,26,28,28,30,32,36}$. In a research study by Aron et al. ${ }^{39}$ that evaluated saccade velocity by video nystagmography in 21 patients with genetically confirmed HD and a control group of 15 subjects, the HD group exhibited decreased saccade velocity when compared with that of the control group. The study also included a baseline analysis and a second evaluation after $18.8+/-7.1$ months. The HD patients showed decreased saccade velocity with the passage of time.

Repeated errors have also been observed for the same task as well as excessive distraction with great instability in maintaining a fixed target ${ }^{14,28,29,30,33}$. Trajectories of saccadic eye movements can be modulated by the presence of a competing visual distractor. It is likely that the superior colliculus controls the initial deviation through competitive lateral interactions. This modulation would be differentially affected in those with HD, given the ramifications of connections between basal ganglia thalamo-cortical circuitry and the superior colliculus ${ }^{38}$.

When HD patients are evaluated with tasks of eye movement, they have a better outcome with visual than with verbal stimuli. However, the disease affects inhibition of the movements. This is shown in the difficulty of limiting eye movement when the subject is asked not to look at a given target ${ }^{14,27,32,38,40,41,42}$. This result suggests that the structures responsible for eye movements, namely basal 
ganglia and the frontal eye fields, are no longer able to regulate inhibitory functions.

The saccadic movements in HD have a long time course, especially when they appear in sequential tasks. This difficulty in organizing and sequencing saccadic movement is a reflection of changes in the supplementary eye field. The corrective saccades seem to be the responsibility of the brainstem and cerebellum. Abnormalities of velocity and latency originate in the frontal-striatal circuit ${ }^{15}$.

Antisaccadic movements have more complex functions ${ }^{13}$. In general, $\mathrm{HD}$ patients are often unable to perform this task, because they are always attracted to the stimuli, resulting in great difficulty in controlling saccades ${ }^{17,43}$. Patients who can produce this type of movement have a greater latency ${ }^{31,44}$. One important consideration is whether these results are influenced by antipsychotic agents that are known to inhibit cortical activity $^{35,45,46}$. To tackle this issue, Arona et al. assessed sixteen patients, eight of whom were drug free and eight on medications. The results indicated no difference between the two groups who both showed abnormalities in the antisaccade task ${ }^{40}$.

Overall, there is a direct relationship between the length of the CAG repeats and the severity of motor, non-motor findings and ocular movement ${ }^{47}$. Interestingly, these results show an association between the number of CAG repeats and the rate of errors on saccadic movement tasks. Ruiz et al..$^{48}$, using video nystagmography, studied reflexive and visually guided horizontal saccades in 32 patients with genetically confirmed $\mathrm{HD}$; nine female and 23 male patients, including six with juvenile onset $\mathrm{HD}, 19$ with adult onset $\mathrm{HD}$, and seven with late onset HD. The results showed a significant difference between the genetic data (length of CAG-repeats) and saccadic abnormalities, with higher repeat numbers corresponding to shorter latency and decreased velocity, as in juvenile HD onset.

Robert et al. ${ }^{49}$ assessed the performance of 12 patients with symptomatic HD, 17 presymptomatic HD and 12 normal controls on saccade tasks In addition to confirming previouslydescribed abnormalities in HD subjects, the authors found changes of optokinetic nystagmus, and errors and negligence of horizontal and vertical saccades. These data suggest that oculomotor abnormalities are a very early manifestation of the

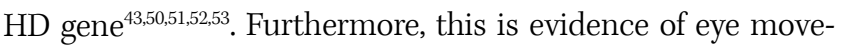
ment abnormalities in individuals with so-called presymptomatic or premanifested HD, ie, those who carry the gene mutation, but have not met diagnostic criteria for HD.

Emphasizing this statement, Patel et al. evaluated saccades and antisaccades in eleven patients with HD, using the UHDRS and the Montreal Cognitive Evaluation. The results indicated that antisaccade motions were altered, as well as saccades with high latencies being shown. The authors suggest there is a connection between cognitive and ocular movement indicating that assessment of eye movements can be used as a biomarker of the disease ${ }^{17}$.

All the principal abnormalities of eye movement in HD can be seen in the Table.

\section{NEUROACANTHOCYTOSIS}

To the best of our knowledge, there are only two published studies of ocular motility in NA. The first study, by Hardie et al. ${ }^{53}$, investigated 16 subjects with chorea-acanthocytosis, two cases of the McLeod phenotype and one case with X-linked abnormality of expression of Kell blood group antigens, whose mean age of onset was 32 years. Neurological disease was associated with acanthocytosis in peripheral blood and normal plasma lipoproteins. Serum creatine kinase activity was increased in 11 cases. Signal abnormalities from the caudate or lentiform nuclei were seen with magnetic resonance imaging in three cases. Cognitive and psychiatric impairment was present in over half of those cases, and over a third had seizures. Depression or absence of tendon reflexes was noted in 13 cases. Chorea, dystonia, tics, involuntary vocalizations and stiffness were seen in 17 cases. Two patients had no movement disorder. The ocular motor function evaluation in this study was only clinical. Ocular motility abnormalities were identified in five of the 19 patients with NA. These abnormalities included impaired saccades and pursuit, limited upgaze, poor convergence, blepharospasm, and gaze apraxia. Eye movements were considered normal in two patients and were not reported for the other 12 patients.

The second article, by Gradstein et al..$^{54}$, reports on latency, speed and stability of the fixation stimulus of slow pursuit, saccade and antisaccade horizontal and vertical eye movements. This is the only study of characterized ocular motor function using eye movement recordings. All patients and control subjects had eye movement recordings made with the magnetic

Table. Oculomotor abnormalities in Huntington's disease.

\begin{tabular}{lcc}
\hline Eye movement & $\begin{array}{c}\text { Patients } \\
\text { affected (\%) }\end{array}$ & $\begin{array}{c}\text { Studies } \\
\text { analyzed }\end{array}$ \\
\hline fixation & 69 & 9 \\
\hline latency (saccade) & 91 & 13 \\
\hline vertical plane & 85 & 16 \\
\hline horizontal plane & 89 & 16 \\
\hline speed (saccade) & 96 & 18 \\
vertical plane & 91 & 16 \\
\hline horizontal plane & 89 & 16 \\
\hline head movement & 85 & 5 \\
\hline vertical plane & 78 & 11 \\
\hline horizontal plane & 85 & 11 \\
\hline hypometria & 81 & 7 \\
vertical plane & 94 & 16 \\
\hline horizontal plane & 73 & 16 \\
\hline saccade reflex & 34 & 6 \\
\hline antisaccades & 93 & 3 \\
vestibulo-ocular reflex & 0 & 3 \\
\hline
\end{tabular}


search coil technique. Subjects viewed a red-diode laser spot target, rear projected onto a tangent screen at $1 \mathrm{~m}$ while the horizontal and vertical positions of the right eye were recorded. The authors included three patients with chorea-acanthocytosis, aged 26, 30, and 44 years, with a mean duration of illness of ten years, as well as six age matched normal volunteers. Patient 1 presented with chorea and vocal tics, dysphagia, dystonia, dysarthria, hypophonia and his parents were distant cousins. Patient 2 presented with dysphagia, dystonia, memory lapses, vocal tics, tongue biting, involuntary stereotypic movements, seizures, cognitive decline and gait difficulties. Patient 3 presented with echolalia, lip-smacking, teeth grinding, clicking and grunting noises, micrographia, deterioration of gait, choreatic movements, hypophonia, seizures and parkinsonism. All patients had horizontal and vertical hypometric and slow saccades. There was also severe difficulty in performing the antisaccade task. These results are similar to those found in HD previously described in this article. The authors speculate that the severe atrophy of the basal ganglia in NA interferes with the ability to perform saccades. They also suggest that the problems with antisaccade tasks are related to frontal lobe dysfunction ${ }^{55}$.

\section{FINAL REMARKS}

The limited studies reviewed here demonstrate the existence of oculomotor abnormalities in SC. The most consistent findings are hypometric saccades and antisaccades that are less likely to be found in individuals with chorea in remission. The main changes in HD subjects are increased latency, decreased speed and accuracy of saccadic movements. These individuals also face significant problems in performing antissacade tasks. There is a correlation between the severity of findings and the number of CAG repeats. Interestingly, presymptomatic individuals also display eye movement abnormalities. The few data on NA patients also show problems with speed, latency and accuracy of horizontal and vertical saccadic and antisaccadic movements.

In conclusion, the reviewed studies show that despite the different etiologies and scarcity of information on SC, HD and NA, these three choreatic disorders present with similar oculomotor abnormalities. It is speculated that the findings result from dysfunction of the oculomotor circuitry caused by either acquired or genetic abnormalities.

\section{References}

1. Cardoso F, Seppi K, Mair KJ, Wenning GK, Poewe W Seminar on choreas. Lancet Neurol. 2006;5(7):589-602. doi:10.1016/S1474-4422(06)70494-X

2. Cardoso F. Huntington disease and other choreas. Neurol Clin. 2009;27(3):719-36. doi:10.1016/j.ncl.2009.04.001

3. Doyle F, Cardoso F, Lopes L, Mendes M, Dias F, Cruz L et al. Infusion of Sydenham's chorea antibodies in striatum with up-regulated dopaminergic receptors: a pilot study to investigate the potential of SC antibodies to increase dopaminergic activity. Neurosci Lett. 2012;523(2):186-9. doi:10.1016/j.neulet.2012.06.073

4. Zomorrodi A, Wald ER. Sydenham's chorea in western Pennsylvania. Pediatrics. 2006;117(4):e675-9. doi:10.1542/peds.2005-1573

5. Cardoso F, Eduardo C, Silva AP, Mota CC. Chorea in fifty consecutive patients with rheumatic fever. Mov Disord. 1997;12(5):701-3. doi:10.1002/mds.870120512

6. Ross CA, Aylward EH, Wild EJ, Langbehn DR, Long JD, Warner $\mathrm{JH}$ et al. Huntington disease: natural history, biomarkers and prospects for therapeutics. Nat Rev Neurol. 2014;10(4):204-16. doi:10.1038/nrneurol.2014.24

7. Harper PS. The epidemiology of Huntington's disease. Hum Genet. 1992;89(4):365-76. doi:10.1007/BF00194305

8. Gusella JF, MacDonald, ME, Ambrose CM, Duyao MP. Molecular genetics of Huntington's disease. Arch Neurol. 1993;50(11):1157-63. doi:10.1001/archneur.1993.00540110037003

9. Jung HH, Danek A, Walker RH. Neuroacanthocytosis syndromes. Orphanet J Rare Dis. 2011;6(1):68. doi:10.1186/1750-1172-6-68

10. Walker RH, Danek A, Dobson-Stone C, Guerrini R, Jung HH, Lafontaine AL et al. Developments in neuroacanthocytosis: expanding the spectrum of choreatic syndromes. Mov Disord. 2006;21(11):1794-805. doi:10.1002/mds.21108

11. Church AJ, Cardoso F, Dale RC, Lees AJ, Thompson EJ, Giovannoni G. Anti-basal ganglia antibodies in acute and persistent Sydenham's chorea. Neurology. 2002;59(2):227-31. doi:10.1212/WNL.59.2.227

12. Harper PS. A specific mutation for Huntington's disease.J Med Genet. 1993;30(12):975-7. doi:10.1136/jmg.30.12.975
13. Pierrot-Deseilligny C, Milea D, Müri RM. Eye movement control by the cerebral cortex. Curr Opin Neurol. 2004;17(1):17-25. doi:10.1097/00019052-200402000-00005

14. Lasker AG, Zee DS. Ocular motor abnormalities in Huntington's disease. Vision Res. 1997;37(24):3639-45. doi:10.1016/S0042-6989(96)00169-1

15. Winograd-Gurvich CT, Georgiou-Karistianis N, Evans A, Millist L, Bradshaw JL, Churchyard A et al. Hypometric primary saccades and increased variability in visually-guided saccades in Huntington's disease. Neuropsychologia. 2003;41(12):1683-92. doi:10.1016/S0028-3932(03)00096-4

16. Ali FR, Michell AW, Barker RA, Carpenter RHS. The use of quantitative oculometry in the assessment of Huntington's disease. Exp Brain Res. 2006;169(2):237-45. doi:10.1007/s00221-005-0143-6

17. Patel SS, Jankovic J, Hood AJ, Jeter CB, Sereno AB. Reflexive and volitional saccades: biomarkers of Huntington disease severity and progression. J Neurol Sci. 2012;313(1-2):35-41. doi:10.1016/j.jns.2011.09.035

18. Rupp J, Dzemidzic M, Blekher T, West J, Hui S, Wojcieszek J et al. Comparison of vertical and horizontal saccade measures and their relation to gray matter changes in premanifest and manifest Huntington disease.J Neurol. 2012;259(2):267-76. doi:10.1007/s00415-011-6172-0

19. Antoniades CA, Mason SL, Carpenter RHS, Barker RA. Huntington's disease: changes in saccades and hand-tapping over 3 years. J Neurol. 2010;257(11):1890-8. doi:10.1007/s00415-010-5632-2

20. Blekher TM, Yee RD, Kirkwood SC, Hake AM, Stout JC, Weaver MR et al. Oculomotor control in asymptomatic and recently diagnosed individuals with the genetic marker for Huntington's disease. Vision Res. 2004;44(23):2729-36. doi:10.1016/j.visres.2004.06.006

21. Munoz DP, Coe BC. Saccade, search and orient: the neural control of saccadic eye movements. Eur J Neurosci. 2001;33(11):1945-7. doi:10.1111/j.1460-9568.2011.07739.x

22. Cairney S, Maruff P, Currie J, Currie BJ. Increased anti-saccade latency is an isolated lingering abnormality in Sydenham chorea.J Neuroophthalmol. 2009;29(2):143-5. doi:10.1097/WN0.0b013e3181a58dfa 
23. Derceux MJ. Choree chronique et paralysie hypertonique du regard. Rev Neurol (Paris). 1945;77:207-8.

24. Andre-Thomas M, Abely X, Ajuriaguerra J, Eullien L. Troubles de l'elevation des globes oculaires dans un cas de choree de Huntington. Rev Neurol (Paris). 1945;77:248-50.

25. Petit $\mathrm{H}$, Milbled G. Anomalies of conjugate ocular movements in Huntington's chorea: application to early detection. Adv Neurol. 1973;1:287-94

26. Becker W, Jürgens R, Kassubek J, Ecker D, Kramer B, Landwehrmeye B. Eye-head coordination in moderately affected Huntington's Disease patients: do head movements facilitate gaze shifts? Exp Brain Res. 2009;192(1):97-112. doi:10.1007/s00221-008-1559-6

27. Leigh RJ, Newman SA, Folstein SE, Lasker AG, Jensen BA. Abnormal ocular motor control in Huntington's disease. Neurology. 1983;33(10):1268-75. doi:10.1212/WNL.33.10.1268

28. Starr A. A disorder of rapid eye movements in Huntington's chorea. Brain. 1967;90(3):545-64. doi:10.1093/brain/90.3.545

29. Avanzini G, Girotti F, Caracen T, Spreafico R. Oculomotor disorders in Huntington's chorea.J Neurol Neurosurg Psychiatr. 1979;42(7):581-9. doi:10.1136/jnnp.42.7.581

30. Oepen G, Clarenbach P, Thoden U. Disturbance of eye movements in Huntington's chorea. Arch Psychiatr Nervenkr (1970). 1981;229(3):205-3.

31. Leigh RJ, Parhad IM, Clark AW, Buettner-Ennever JA, Folstein SE. Brainstem findings in Huntington's disease: possible mechanisms for slow vertical saccades. J Neurol Sci. 1985;71(2-3):247-56. doi:10.1016/0022-510X(85)90063-2

32. Bollen E, Reulen JPH, Den Heyer JC, Van der Kamp W, Roos RAC, Buruma OJS. Horizontal and vertical saccadic eye movement abnormalities in Huntington's chorea. J Neurol Sci. 1986;74(1):11-22. doi:10.1016/0022-510X(86)90187-5

33. Tian JR, Zee DS, Lasker AG, Folstein SE. Saccades in Huntington's disease: predictive tracking and interaction between release of fixation and initiation of saccades. Neurology. 1991;41(6):875-81. doi:10.1212/WNL.41.6.875

34. Lasker AG, Zee DS, Hain TC, Folstein SE, Singer HS. Saccades in Huntington's disease: initiation defects and distractibility. Neurology. 1987;37(3):364-70. doi:10.1212/WNL.37.3.364

35. Rubin AJ, King WM, Reinbold KA, Shoulson I. Quantitative longitudinal assessment of saccades in Huntington's disease. J Clin Neuroophthalmol. 1993;13(1):59-66.

36. Tsai TT, Lasker A, Zee DS. Visual atention in Huntington's disease. Neuropsychologla. 1995;33(12):1617-26. doi:10.1016/0028-3932(95)00094-1

37. Fielding J, Georgiou-Karistianis N, Bradshaw J, Millist L, Churchyard A, White $\mathrm{O}$. Accelerated time-course of inhibition of return in Huntington's disease. Behav Brain Res. 2006;166(2):211-9. doi:10.1016/j.bbr.2005.08.004

38. Ruiz GPJ, Cenjor C, Ulmer E, Hernández J, Cantarero S, Fanjul S, García de Yébenes J. [Speed of ocular saccades in Huntington disease: prospective study]. Neurologia. 2001;16(2):70-3. Spanish.

39. Aron AR, Sahakian BJ, Robbins TW. Distractibility during selection-for-action: differential deficits in Huntington's disease and following frontal lobe damage. Neuropsychologia. 2003;41(9):1137-47. doi:10.1016/S0028-3932(03)00034-4
40. Kirkham TH, Guitton DA. A quantitative study of abnormal eye movements in Huntington's chorea using the scleral search coil technique. Neuro-Ophthalmol. 1984;4(1):277-38. doi:10.3109/01658108409019493

41. Collewijn H, Went LN, Tamminga EP, Vegter-Van der Vlis M. Oculomotor defects in patients with Huntington's disease and their offspring. J Neurol Sci. 1988;86(2-3):307-20. doi:10.1016/0022-510X(88)90107-4

42. Blekher T, Johnson SA, Marshall J, White K, Hui S, Weaver M et al. Saccades in presymptomatic and early stages of Huntington disease. Neurology. 2006;67(3):394-9. doi:10.1212/01.wnl.0000227890.87398.c1

43. Grabska N, Rudzińska M, Wójcik-Pędziwiatr M, Michalski M, Stawek J, Szczudlik A. Saccadic eye movements in juvenile variant of Huntington disease. Neurol Neurochir Pol. 2014;48(4):236-41. doi:10.1016/j.pjnns.2014.06.003

44. Dursun SM, BurkeJG, AndrewSH, Mlynik-Szmid A, Reveley MA. The effects of antipsychotic medication on saccadic eye movement abnormalities in Huntignton's disease. Prog Neuropsydlopharmacol Biol Psychatry. 2000;24(6):889-96. doi:10.1016/S0278-5846(00)00116-0

45. Reilly JL, Lencer R, Bishop JR, Keedy S, Sweeney JA. Pharmacological treatment effects on eye movement control. Brain Cogn. 2008;68(3):415-35. doi:10.1016/j.bandc.2008.08.026

46. Sánchez-Pernaute R, García-Segura JM, Barrio Alba A, Viaño J, Yébenes JG. Clinical correlation of striatal 1H MRS changes in Huntington's disease. Neurology. 1999;53(4):806-12. doi:10.1212/WNL.53.4.806

47. Kirkwood SC, Siemers E, Hodes ME, Conneally PM, Christian JC Foroud T. Subtle changes among presymptomatic carriers of the Huntington's disease gene. J Neurol Neurosurg Psychiatry. 2000;69(6):773-9. doi:10.1136/jnnp.69.6.773

48. Ruiz PG, Fontán A, Cenjor C, Ulmer E, Tortosa EG, Pernaute RS. [Disorders in gaze saccades in Huntington disease. Clinical correlations]. Nervenarzt. 2001;72(6):437-40. German.

49. Robert MPA, Nachev PC, Hicks SL, Golding CVP, Tabrizi SJ, Kennard C. Saccadometry of conditional rules in presymptomatic Huntington's disease. Ann N Y Acad Sci. 2009;1164(1):444-50. doi:10.1111/j.1749-6632.2008.03736.x

50. Golding CVP, Danchaivijitr C, Hodgson TL, Tabrizi SJ, Kennard C. Identification of an oculomotor biomarker of preclinical Huntington disease. Neurology. 2006;67:485-7. doi:10.1212/01. wnl.0000218215.43328.88

51. Biglan KM, Ross CA, Langbehn DR, Aylward EH, Stout JC, Queller S et al. Motor abnormalities in premanifest persons with Huntington's. Mov Disord. 2009;24(12):1763-72. doi:10.1002/mds.22601

52. Hicks SL, Robert MP, Golding CV, Tabrizi SJ, Kennard C. Oculomotor deficits indicate the progression of Huntington's disease. Prog Brain Res. 2008;171:555-8. doi:10.1016/S0079-6123(08)00678-X

53. Hardie RJ, Pullon HW, Harding AE, Owen JS, Pires M, Daniels GL et al. Neuroacanthocytosis: a clinical, haematological and pathological study of 19 cases. Brain. 1991;114(1):13-49. doi:

54. Gradstein L, Danek A, Grafman J, Fitzgibbon EJ. Eye movements in chorea-acanthocytosis. Invest Ophthalmol Vis Sci. 2005;46(6):1979-87. doi:10.1167/iovs.04-1309

55. Blekher T, Weaver MR, Marshall J, Hui S, Jackson JG, Stout JC, Beristain X, Wojcieszek J, Yee RD, Foroud TM. Visual scanning and cognitive performance in prediagnostic and early-stage Huntington's disease. Movement Disorders, 2009, v. 24, n. 4, p. 533-540. 